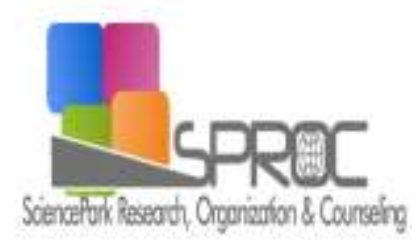

http://sproc.org/ojs/index.php/gjcs

\title{
Compression internet access methods of Univercities in Turkey
}

Mirsat Yeşiltepe *,

İrem Yılmaz,

Muhammet Kurulay,

Suggested Citation:

Global Journal of Computer Sciences 5

Abstract 


\section{Authentications}

2. Form Authentication

\section{Windows Authentication}

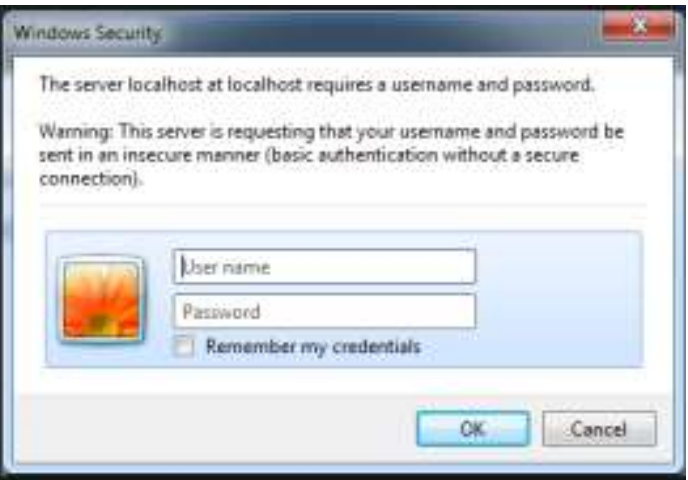

Sign In

Username :

Password:

Sign In 
3.1. Anonymous Authentication

3.2. Basic Authentication

3.3. Digest Authentication

3.3.1. Active Directory

3.3.1.1. Advantages of Directory Service

3.4. Integrated Windows Authentication

3.4.1. Kerberos Technology 
4. Comparasion of Form Authentication and Windows Authentication

5. Testing 


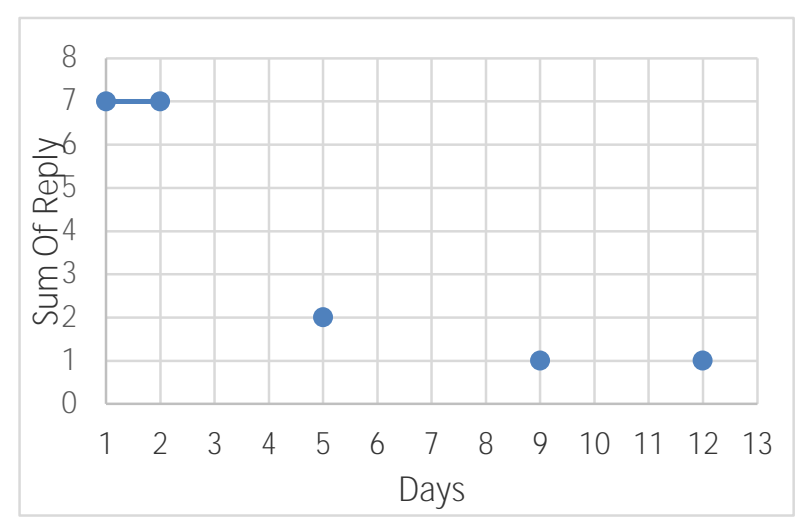

\section{Conclusion}

\section{References}

Cryptology-CRYPTO'93

Advances in

Communications, IEEE 1

Personal

Engineering in Medicine and Biology Society, 2005. IEEE-EMBS 2005. 27th Annual International Conference of the Information security management handbook

ASP.NET güvenlik II form tabanlı güvenlik

What is the difference between basic auth and form based auth.

Windows authentication vs forms authentication.

Difference between claim based authentication and classic windows authentication. 
Windows authentication dot net security part 2 
